\title{
Analysis of the Control Effect and Parameter Optimisation of Urban Surface Deformation in Underground Coal Mining with Solid Backfilling
}

\author{
Jiaqi Wang $\mathbb{D}^{1}{ }_{1}^{1}$ Jixiong Zhang $\mathbb{D}^{2}{ }^{2}$ Qiang Zhang $\mathbb{D}^{2}{ }^{2}$ Zhongya Wu, ${ }^{1}$ Qi Zhang ${ }^{1}{ }^{1}$ \\ Yunbo Wang, ${ }^{1}$ and Difa Gao ${ }^{1}$ \\ ${ }^{1}$ State Key Laboratory of Coal Resources and Safe Mining, School of Mines, China University of Mining and Technology, Xuzhou, \\ Jiangsu Province 22116, China \\ ${ }^{2}$ School of Mines, China University of Mining and Technology, Xuzhou, Jiangsu Province 22116, China
}

Correspondence should be addressed to Jixiong Zhang; zjxiong@163.com and Qiang Zhang; leafkky@163.com

Received 12 April 2021; Accepted 29 July 2021; Published 17 August 2021

Academic Editor: Qianqian Wang

Copyright (c) 2021 Jiaqi Wang et al. This is an open access article distributed under the Creative Commons Attribution License, which permits unrestricted use, distribution, and reproduction in any medium, provided the original work is properly cited.

To solve the problems of surface deformation and destruction of buildings caused by urban mining and realise the coordinated development of mining cities, the solid backfilling method was used to extract coal resources beneath the buildings of Tangshan. Based on surface deformation monitoring data of the continuously operating reference station (CORS) system for the past 5 years, the surface deformation process caused by solid backfilling was analysed. The final results revealed a maximum surface subsidence of $66 \mathrm{~mm}$ in the $T$ zone coal area and $31 \mathrm{~mm}$ in the $F$ zone area. Furthermore, the surface control effects of the caving method and the solid backfilling method were compared and analysed, and it was shown that solid backfilling could meet the surface building setup requirements. Moreover, based on the probability integral method, the effects on surface deformation due to the surface length of the $F$ zone, compression ratio, and coal pillar width were analysed, and the effects on the prediction results due to the subsidence factor, tangent of the major effective angle, and offset distance of the inflection point were studied. The results showed that the compression ratio is the main factor controlling the surface deformation and that it should be kept above $80 \%$ for solid backfilling of urban mines. The subsidence factor should be 0.82 , and the tangent of the major effective angle should be 2.15 when the surface subsidence of solid backfilling is to be predicted. This paper provides a technical reference for the realisation of urban mining with solid backfilling.

\section{Introduction}

In recent years, the rapid development of China's economy has increased the demand for coal resources. In 2019 alone, China's coal production reached 3.85 billion tons, a year-onyear increase of $4 \%[1,2]$. Such large-scale coal resource development has brought exhaustion of conventional coal resources, and some mines have had to explore coal resources beneath buildings, railways, and water bodies, which directly affects and restricts the harmonious development of ecology and society around the mining area. China's production of coal resources from beneath buildings, railways, and water bodies under unified allocation alone has reached 140 billion tons, with the amount of coal resources under buildings accounting for $70 \%$ of the total amount $[3,4]$. When such coal resources are mined, the surface deformation causes buildings to be stretched, compressed, and bent, thus causing various degrees of damage and collapse hazards to the buildings. Mining is also accompanied by the discharge of a large amount of solid waste gangue, which pollutes the environment and encroaches on the land. All of these problems cause serious conflicts in the development of a mining city.

The coal industry has been actively exploring ways to coordinate the development of coal mining and mining cities and has done considerable research and practical work. Solid backfill mining $[5,6]$, which uses backfill to control rock movement and surface subsidence, has become the 
main technology to solve the conflicts between the development of the mine and the city. This technology has existed for some time and has been applied in more than 20 mines in China, effectively solving the problem of redundant resource extraction. However, the long-term practice has shown that even the solid backfill mining method can cause large-scale movement and deformation of the ground surface. Current research on this problem has focused mainly on how the fill body controls rock movement, monitoring of surface movement and deformation, and analysis of disasters caused by surface deformation.

Many scholars have researched these problems. Miao et al. [7-9], Zhang et al. [10-12], and Qiang et al. [13, 14] have advanced the equivalent mining height theory, key layer control theory, main roof control theory, and immediate roof control theory. These studies concluded that solid backfill mining can be regarded as extremely thin coal seam mining, allowing the surface subsidence to be controlled. The control targets for solid backfilling in the rock are the key layer, the main roof, and the immediate roof, with the first being the most difficult target and the last being the most precise target. Guo et al. [15-17], Cha et al. [18, 19], and Yao et al. [20,21] proposed the use of the probability integral method to describe patterns of surface deformation, established a prediction model parameter system for surface subsidence with solid backfilling, and actually measured surface subsidence results using an electronic total station. Fei et al. [22] and Niu et al. [23] further analysed surface deformation characteristics using the analytic hierarchy process evaluation model and evaluation system.

The methods of surface deformation monitoring used in the aforementioned studies are not continuous and cannot show the surface deformation process caused by solid backfill mining because only the control effect of solid backfilling on the overlying rock layer was investigated. In this paper, taking the Tangshan mine as an example, 5 years of continuous surface subsidence data monitored by the continuously operating reference station (CORS) system were used to study the surface subsidence control effect of solid backfill mining. The effects on surface deformation due to surface length, compression ratio, and working surface arrangement were analysed. The effects of the subsidence factor, the tangent of a major effective angle, and offset distance of the inflection point on the prediction results were also studied. Finally, the ranges of the compression ratio control index and the surface subsidence prediction parameters for solid backfill mining in urban mines were obtained.

\section{Research Area and Methods}

2.1. Mining Geological Conditions. Tangshan mine, with a field area of $37.28 \mathrm{~km}^{2}$ and a mining area of $55 \mathrm{~km}^{2}$, is located in Lu'nan District, Tangshan City, Hebei Province. It is the only state-owned mega coal mine in China located in a city centre with convenient transportation access. Tangshan mine uses the progressive mining area development method of inclined shafts. At present, there are 7 vertical shafts, which divide the mine into 10 production areas. There are no large-scale faults in the Tangshan minefield, and the main coal seams are 5 th, 8 th, 9th, and 12 th, with average thicknesses of $2.4,3.7,3.5$, and $6.4 \mathrm{~m}$, respectively. Among these, the 5 th coal seam has an immediate roof consisting of $4.8 \mathrm{~m}$ thick fine sandstone and a bottom plate of $0.9 \mathrm{~m}$ thick mudstone, whereas the 9th coal seam has an immediate roof consisting of $0.7 \mathrm{~m}$ thick mudstone and a bottom plate of $1.0 \mathrm{~m}$ thick sandy mudstone. The geographical location and working face distribution of the Tangshan mine are shown in Figure 1.

As shown in Figure 2, the production area of Tangshan mine is located beneath the city. The main coal areas are the $T$ zone and the $F$ zone. The $T$ zone has an area of $2.01 \mathrm{~km}^{2}$ and 30.366 million tons of coal, of which 1.427 million tons have been mined to date. There are 67 community and office buildings on the surface. The $F$ zone has an area of $1.27 \mathrm{~km}^{2}$ and 34.413 million tons of coal, of which 34.26 million tons have been mined. Production and living facilities of the mine itself and a park exist at the surface. Figure 2 shows a comparison between the surface and subsurface structures. Figure 3 shows the arrangement of surface deformation observation points.

As examples, the $\mathrm{T}_{3} 292$ working face and the $\mathrm{F} 5001$ working face of the Tangshan mine are shown schematically in Figure 4. The $\mathrm{T}_{3} 292$ working face has a length of $90 \mathrm{~m}$, is elevated at an angle, and was in operation from 1 March 2013 to 1 April 2017. The F5001 working face has a length of $66 \mathrm{~m}$, is also elevated at an angle, and was in operation from 1 January 2016 to 1 September 2017.

The $\mathrm{T}_{3} 292$ working face has two surface observation lines, that is, lines A and L (Figure 5), with 22 points online A and 8 points online L. The F5001 working face has one surface observation line, line $\mathrm{F}$, with a total of 22 points. The F5002 working face has four surface observation lines, N, S, $\mathrm{W}$, and $\mathrm{E}$.

The test used the surface subsidence monitoring data obtained from 1 January 2015 to 1 December 2019 as a reference to analyse the surface subsidence after mining on the $\mathrm{T}_{3} 292$ working face, F5001 working face, and F5002 working face. The monitoring data span more than 5 years and so can reflect the long-term surface deformation after solid backfill mining.

2.2. Solid Backfilling Control Method. The solid backfill mining method, which is carried out through integrated mechanised mining operations on working faces, is used for mining under urban buildings. In the solid backfill coal mining system, the gangue is transported from the surface feeding well and underground separation chamber to the working faces, is then filled into the goaf using key equipment such as the multihole bottom dump conveyor and hydraulic support system for solid backfilling, and is finally compacted by the ramming mechanism behind the hydraulic support system. From 2015 to 2019, the surface feeding well accumulated 604,600 tons of gangue, and the underground separation system accumulated 421,100 tons of gangue. The backfilling system, shown in the basic concept in Figure 4, is running well. 


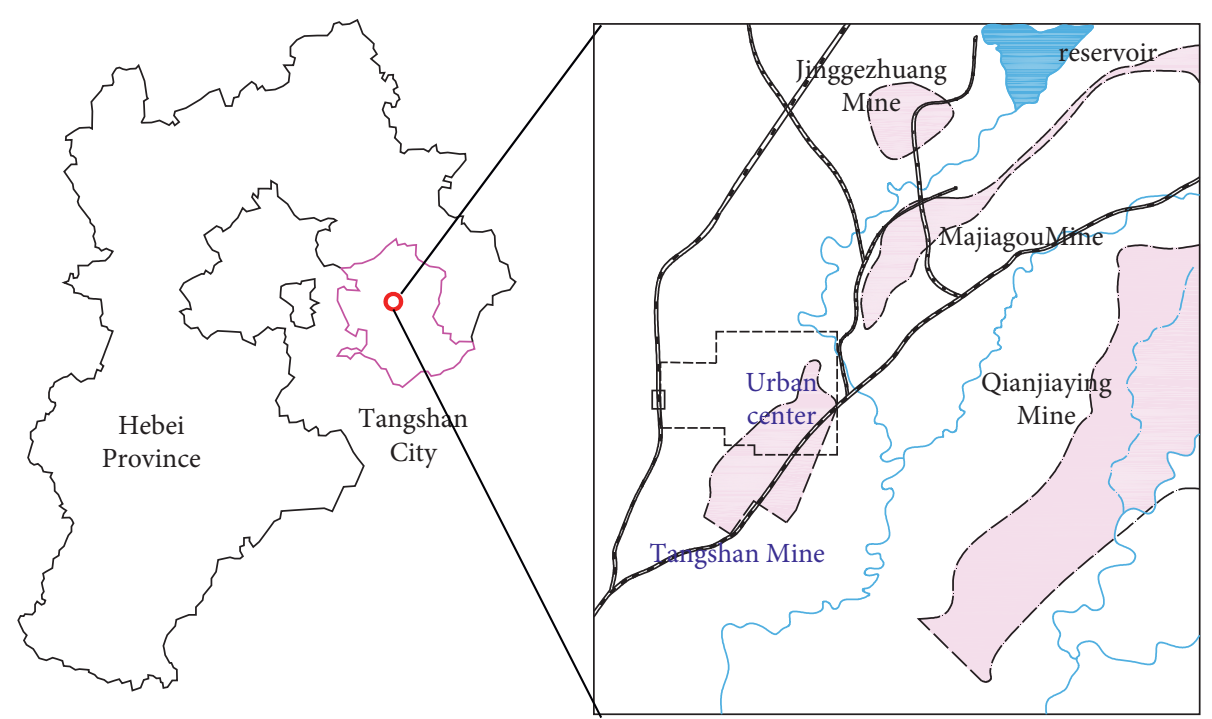

(a)

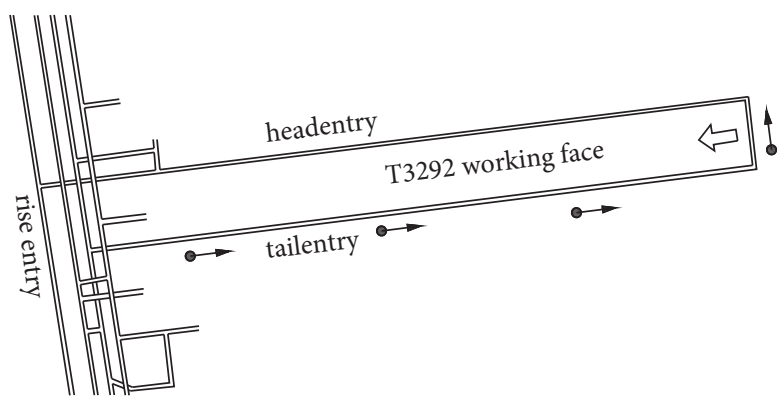

$\multimap$ gangue transportation route

(b)

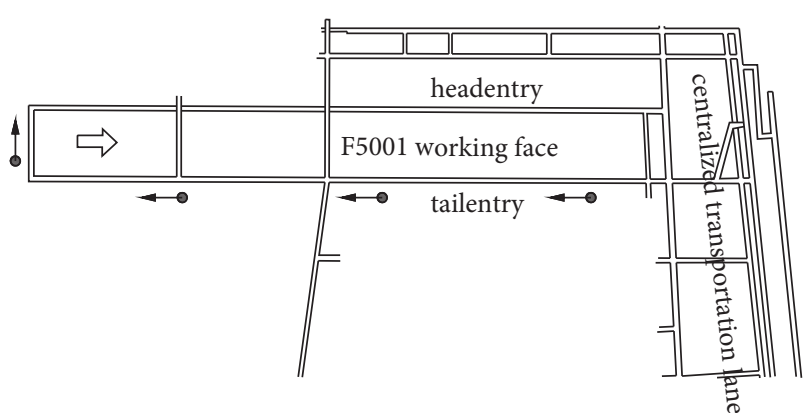

$\multimap$ gangue transportation route

FIgURE 1: Geographical location and working face distribution of Tangshan mine: (a) location of Tangshan mine, (b) layout of T3292 working face, and (c) layout of F5001 working face.
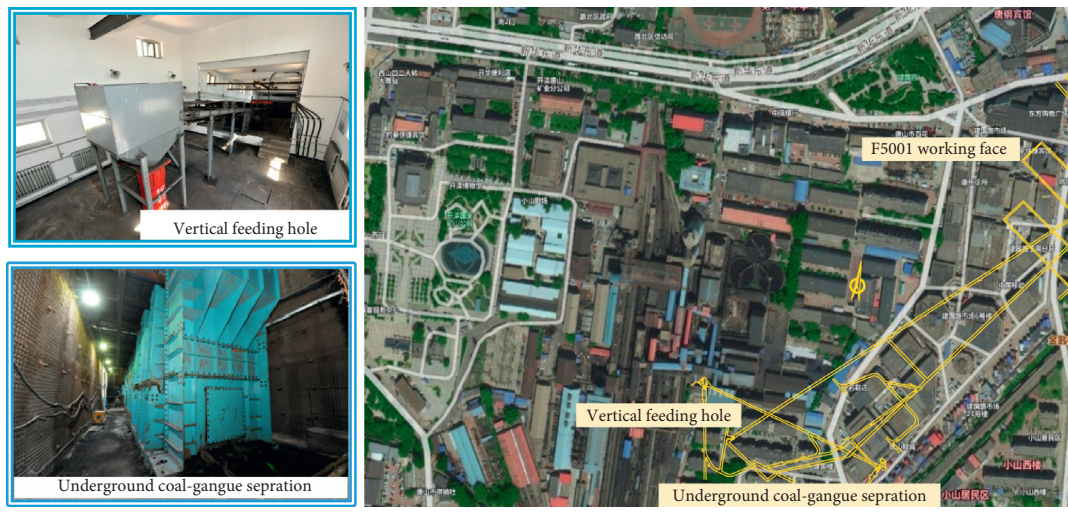

FIgURE 2: Tangshan mine surface-subsurface comparison.
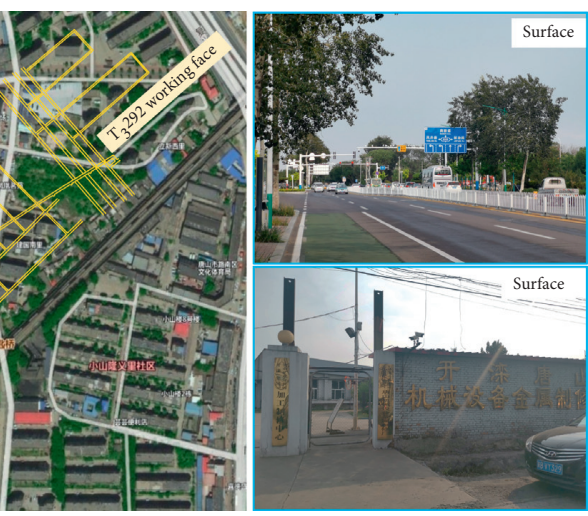

$2.0 \mathrm{~mm} / \mathrm{m}$, curvature less than $0.2 \mathrm{~mm} / \mathrm{m}^{2}$, and inclination less than $3.0 \mathrm{~mm} / \mathrm{m}$.

\subsection{Analysis Method of Surface Deformation}

2.3.1. Monitoring Method. Monitoring the subsidence and deformation of the surface, buildings, and other structures is main structures of the surface buildings above Tangshan mine are brick-concrete, brick-wood, and steel structures, which meet the national requirements for Class II-III protection. When mining the coal resources beneath the city, the buildings must be kept below the Class I damage level after mining, that is, horizontal deformation less than 


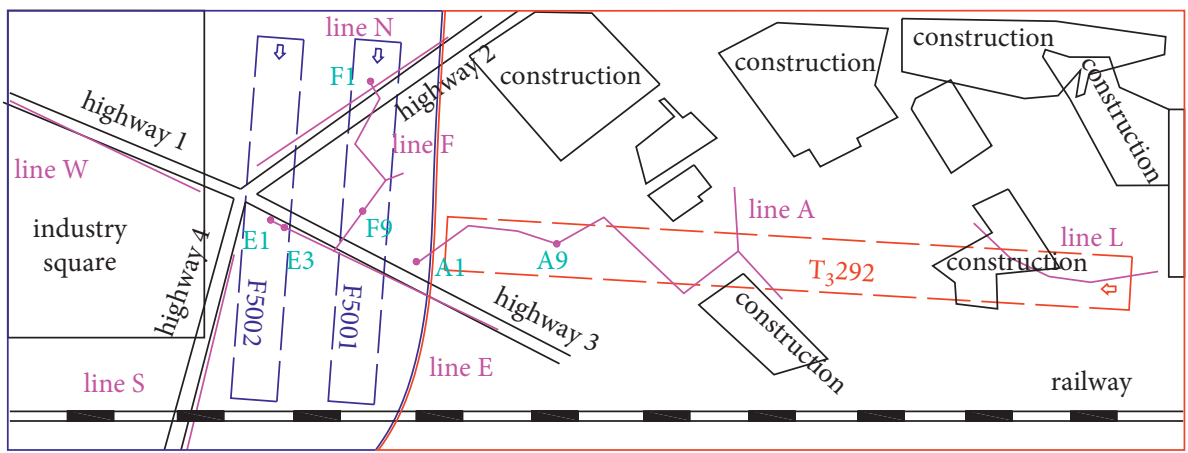

FiguRE 3: Arrangement of surface deformation observation points on solid backfill mining faces.

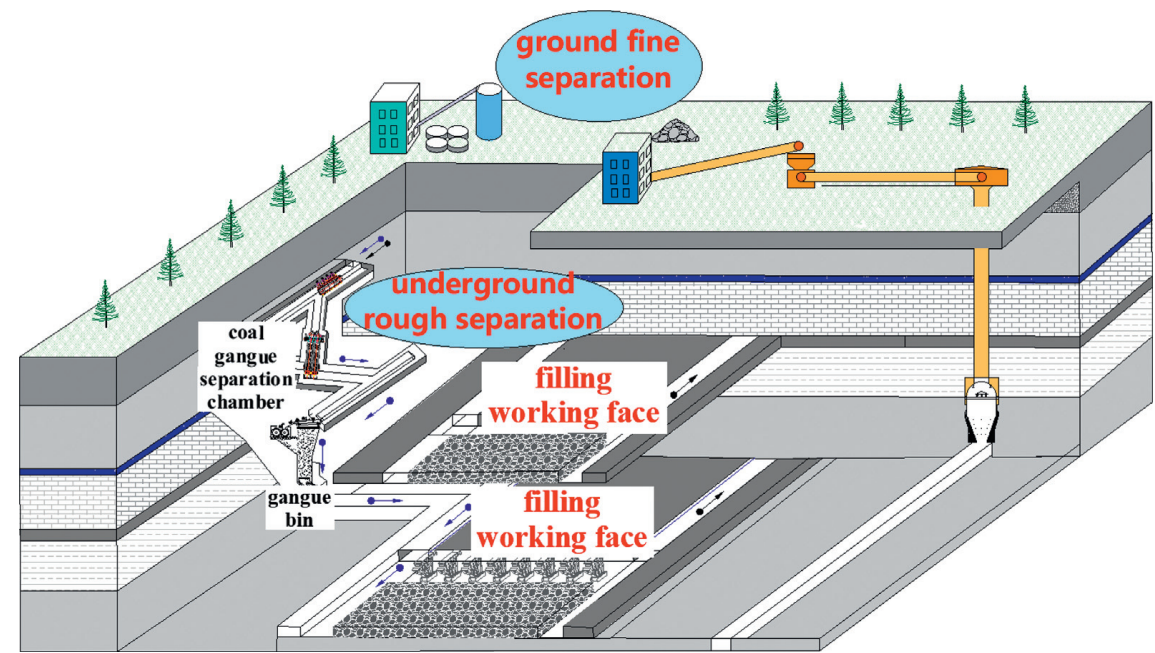

Figure 4: Basic concept of solid fill mining.

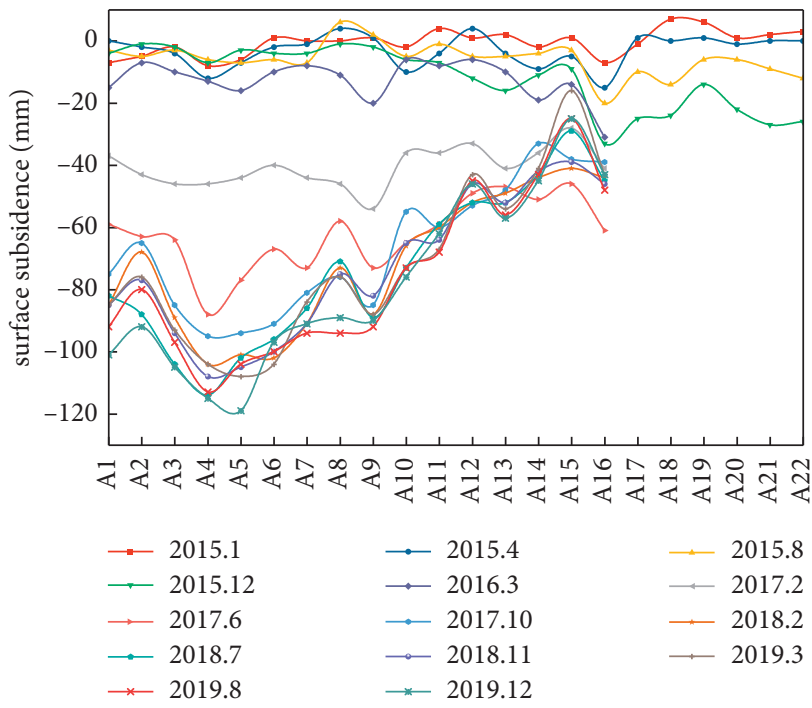

(a)

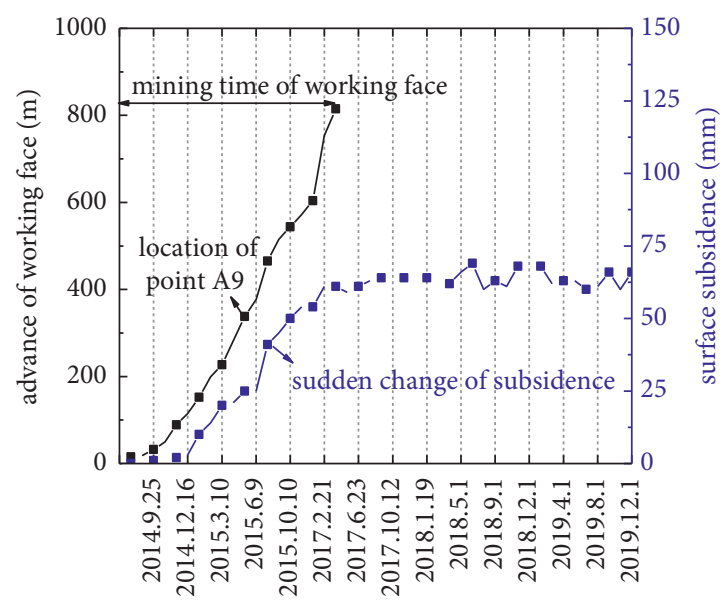

(b)

FIGURE 5: Surface subsidence values (a) on line A for each time period and (b) for each time period at measuring point $A 9$. 
an important task in the process of mining beneath a city. The conventional monitoring methods used for the Tangshan mine include mainly theodolite tracking, total station monitoring, and water level monitoring. The main problems faced in the monitoring process are addressed below. The accuracy of the conventional monitoring methods is not very high. Moreover, the detection process is easily affected by rain, snow, and the mutual obstruction of the surface buildings. In addition, conventional monitoring systems are not capable of continuous monitoring.

The CORS system for intelligent monitoring of surface subsidence can carry out continuous and uninterrupted observation and achieve real-time collection, transmission, calculation, and analysis of data within the subsidence range. The CORS system applied in the Tangshan mine is equipped with China's Beidou Satellite Navigation System, which is compatible with the United States' GPS system and Russia's GLONASS system, to improve the accuracy of surface subsidence deformation measurement. The CORS system basically consists of a data centre, a reference station, a data communication subsystem, and a user application subsystem. It achieves all-weather, fully automatic, and precise positioning through satellite positioning technology, the reference station, and the Internet. The base station and Class I and II measuring points of the Tangshan mine are shown in Figure 6.

2.3.2. Prediction Method. The probability integral method is used to estimate the surface movement and deformation. Its calculation principle is as follows.

The calculation of subsidence value at any point on the surface is shown in equation (1). The calculation of the inclination deformation value of any point on the surface is shown in equation (2). The calculation of curvature deformation value of any point on the surface is shown in equation (3). The calculation of horizontal movement value of any point on the surface is shown in equation (4). The calculation of horizontal deformation at any point on the surface is shown in equation (5).

$$
\begin{aligned}
W(x) & =\frac{W_{0}}{2}\left[\operatorname{erf}\left(\frac{\sqrt{\pi}}{r} x\right)+1\right], \\
i(x) & =\frac{W_{0}}{r} e^{\left(-\pi\left(x^{2} / r^{2}\right)\right)}, \\
k(x) & =-2 \pi \frac{W_{0}}{r^{3}} x e^{-\left(\pi\left(x^{2} / r^{2}\right)\right)}, \\
U(x) & =b W_{0} e^{-\left(\pi\left(x^{2} / r^{2}\right)\right)}, \\
\varepsilon(x) & =-2 \pi b \frac{W_{0}}{r^{2}} x e^{\left(-\pi\left(x^{2} / r^{2}\right)\right)},
\end{aligned}
$$

where $W_{0}=M_{\mathrm{e}} \cdot q \cdot \cos \alpha$ and $r=H / \tan \beta . M_{\mathrm{e}}$ is the equivalent mining height of solid dense filling mining; $q$ is the surface subsidence coefficient of solid dense filling mining; $b$ is the horizontal moving coefficient; $\tan \beta$ is the tangent of the main influence angle; and $\alpha$ is the dip angle of mining seam.
2.3.3. Test Scheme for the Cause of Surface Subsidence. Taking the $F$ zone as an example, under the mining geological conditions of the Tangshan mine, it is considered that the surface subsidence above the $F$ zone was influenced by the face length, the compression ratio of the working face, and the width of the coal pillar in the section. To analyse the causes of surface subsidence, 15 sets of test plans were designed, as shown in Table 1. Tests 1-5 analysed the effect of face length on surface deformation parameters, tests 6-10 analysed the effect of compression ratio on surface deformation parameters, and tests 11-15 analysed the effect of coal pillar width on surface deformation parameters.

The surface deformation prediction uses the probability integral method based on equivalent mining height. Due to the presence of a large number of primary fissures, joints, and strata in the subsiding rock, it is feasible to predict surface movement and deformation by the probability integral method of the random medium.

In comparison with the caving method, when the probability integral method is used to predict surface subsidence for solid backfill mining, prediction parameters such as the subsidence factor, tangent of a major effective angle, and offset distance of the inflection point change greatly. Therefore, these prediction parameters are considered to have a relatively large influence on the prediction results. Using a compression ratio of $0.8,15$ sets of test plans were designed to analyse the prediction results of surface deformation, and the plans are shown in Table 2. Tests 1-5 analysed the influence of the subsidence factor on the projected results, tests 6-10 analysed the influence of the tangent of the major effective angle on the prediction results, and tests 11-15 analysed the influence of the offset distance of the inflection point on the surface deformation parameters.

\section{Results and Interpretation}

\subsection{Monitoring and Analysis of Filling Surface Deformation}

3.1.1. Surface Monitoring Results in Area T. The $\mathrm{T}_{3} 292$ working face was put into production in March 2013 and stopped being used in April 2017. Line A, measuring surface subsidence in the $T$ zone, crosses the middle of the $T_{3} 292$ working face, and the projected positions of the selected measuring points below the working face are located at a distance of $340 \mathrm{~m}$ from the open-off cut of the working face. The surface subsidence data of each measuring point online A were obtained by processing the monitoring data, as shown in Figure 5(a). The surface subsidence data of each time period at the $A 9$ measuring point are shown in Figure 5(b).

As shown in Figure 5(b), the surface subsidence increased slowly from the start of mining on the working face to June 2015, with the subsidence value lower than $25 \mathrm{~mm}$. Between June 2017 and August 2017, after the working face was pushed $90 \mathrm{~m}$ beyond measuring point $A 9$, the surface subsidence value increased significantly, with its maximum value reaching $41 \mathrm{~mm}$ at measuring point F16. In April 2017, the working face had been mined completely. By 

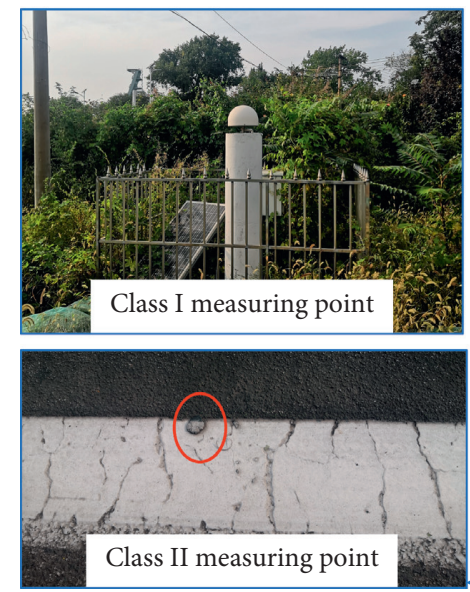

Class II measuring point
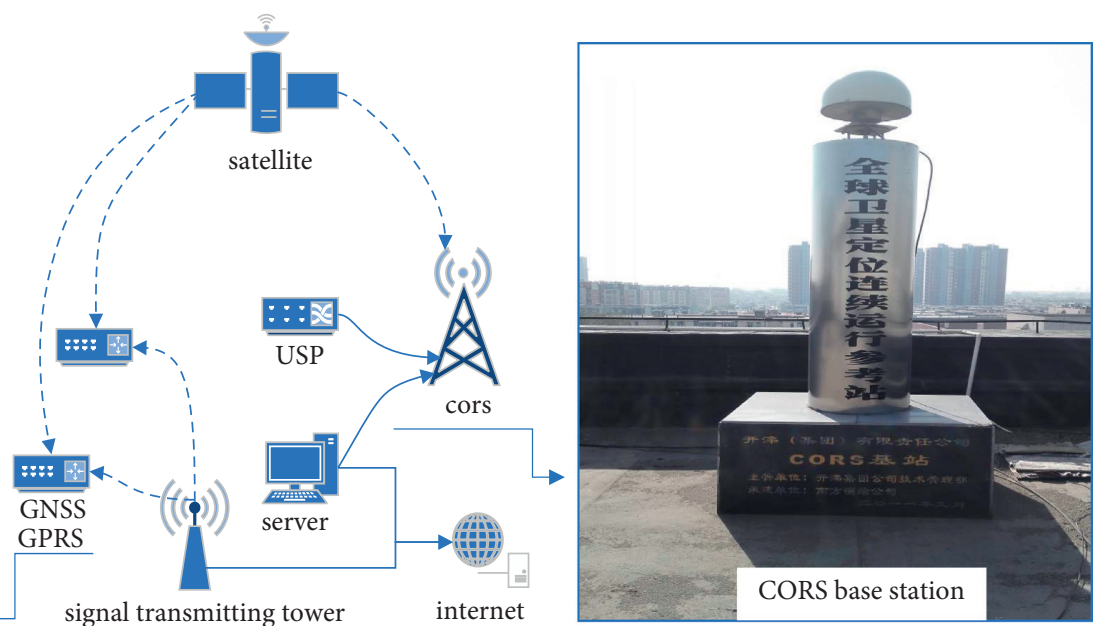

Figure 6: CORS base station and measuring points at Tangshan mine.

TABLE 1: Description of test plans.

\begin{tabular}{lccc}
\hline Factor & Face length & Compression ratio & Coal pillar width \\
\hline Test 1 & 40 & 0.8 & 5 \\
Test 2 & 50 & 0.8 & 5 \\
Test 3 & 60 & 0.8 & 5 \\
Test 4 & 70 & 0.8 & 5 \\
Test 5 & 80 & 0.8 & 5 \\
Test 6 & 60 & 0.3 & 5 \\
Test 7 & 60 & 0.6 & 5 \\
Test 8 & 60 & 0.7 & 5 \\
Test 9 & 60 & 0.8 & 5 \\
Test 10 & 60 & 0.9 & 5 \\
Test 11 & 60 & 0.8 & 0.8 \\
Test 12 & 60 & 0.8 & 5 \\
Test 13 & 60 & 0.8 & 10 \\
Test 14 & 60 & 0.8 & 15 \\
Test 15 & 60 & 0.8 & 20 \\
\hline
\end{tabular}

TABle 2: Description of test plans.

\begin{tabular}{lccc}
\hline Factor & Subsidence factor & Tangent of major effective angle & Offset distance of the inflection point \\
\hline Test 1 & 0.78 & 2.15 & 0.086 \\
Test 2 & 0.80 & 2.15 & 0.086 \\
Test 3 & 0.82 & 2.15 & 0.086 \\
Test 4 & 0.84 & 2.15 & 0.086 \\
Test 5 & 0.86 & 2.15 & 0.086 \\
Test 6 & 0.82 & 1.75 & 0.086 \\
Test 7 & 0.82 & 1.95 & 0.086 \\
Test 8 & 0.82 & 2.15 & 0.086 \\
Test 9 & 0.82 & 2.35 & 0.086 \\
Test 10 & 0.82 & 2.55 & 0.086 \\
Test 11 & 0.82 & 2.15 & 0.006 \\
Test 12 & 0.82 & 2.15 & 0.046 \\
Test 13 & 0.82 & 2.15 & 0.086 \\
Test 14 & 0.82 & 2.15 & 0.126 \\
Test 15 & 0.82 & 2.15 & 0.166 \\
\hline
\end{tabular}

December 2019, the $\mathrm{T}_{3} 292$ working face had reached full mining impact, and its maximum subsidence had increased to $66 \mathrm{~mm}$. From the time of sudden subsidence to full mining impact, the subsidence value increased by approximately $37.8 \%$.
The CORS monitoring system indicated a final maximum surface tilt deformation of $0.76 \mathrm{~mm} / \mathrm{m}$, a maximum curvature deformation of $0.064 \mathrm{~mm} / \mathrm{m}^{2}$, and a maximum horizontal deformation of $50.6 \mathrm{~mm}$, or $1.53 \mathrm{~mm} / \mathrm{m}$, which meets the surface building protection requirements. 


\subsubsection{Surface Monitoring Results in Area F}

(1) F5001 Working Face. The F5001 working face was put into production in October 2016 and stopped being used in September 2017. Line F, measuring surface subsidence in the $F$ zone, crosses the middle of the F5001 working face, and the projected positions of the selected measuring points under the working face are located at $400 \mathrm{~m}$ from the open-off cut of the working face. The monitoring data were processed to obtain the surface subsidence data of each measuring point online F, as shown in Figure 7(a). The surface subsidence data of each time period of measuring point F9 are shown in Figure 7(b).

As shown in Figure $7(\mathrm{~b})$, the surface subsidence increased slowly, with subsidence values lower than $10 \mathrm{~mm}$, from the start of the mining on the working face to May 2017. Between June 2017 and July 2017, after the working face had pushed through $66 \mathrm{~m}$ from measuring point $F 9$, the surface subsidence increased significantly, with a maximum value of $19 \mathrm{~mm}$ at measuring point $F 16$. In November 2017, the working face was mined completely, and by April 2018, the F5001 working face had reached full mining impact, and its maximum subsidence had increased to $31 \mathrm{~mm}$. From sudden subsidence to full mining impact, the time elapsed was approximately 8 months, and the subsidence value had increased by approximately $38.7 \%$.

The CORS monitoring system indicated a final maximum surface tilt deformation of $1.65 \mathrm{~mm} / \mathrm{m}$, a maximum curvature deformation of $0.094 \mathrm{~mm} / \mathrm{m}^{2}$, and a maximum horizontal deformation of $16.1 \mathrm{~mm}$, or $1.25 \mathrm{~mm} / \mathrm{m}$, which meets the surface building protection requirements.

(2) F5002 Working Face. The F5002 working face was put into production in November 2017 and stopped being used in December 2018. Line E, measuring surface subsidence in the $F$ zone, crosses the middle of the F5002 working face, and the projected positions of the selected measuring points below the working face are located at $400 \mathrm{~m}$ from the open-off cut of the working face. The monitoring data were processed to obtain the surface subsidence data of each measuring point online $\mathrm{E}$, as shown in Figure 8(a). The surface subsidence data of each time period of measuring point E3 are shown in Figure 8(b). There was almost no increase in surface subsidence from the start of mining on the working face to September 2018. Mining on the working face was fully stopped in December 2018, and by July 2019, the surface subsidence of the F5002 working face had reached $17 \mathrm{~mm}$. By December 2019, the full mining impact had been reached, and the maximum increase in subsidence was $25 \mathrm{~mm}$. From sudden subsidence to full mining impact, the time elapsed was approximately 5 months, and there was an increase in subsidence value of approximately $47.1 \%$.

The CORS monitoring system indicated a final maximum surface tilt deformation of $0.29 \mathrm{~mm} / \mathrm{m}$, a maximum curvature deformation of $0.012 \mathrm{~mm} / \mathrm{m}^{2}$, and a maximum horizontal deformation of $7.84 \mathrm{~mm}$, or $0.81 \mathrm{~mm} / \mathrm{m}$, which meets the surface building protection requirements.
3.2. Analysis of Surface Deformation Monitoring by Caving Method. Observation of the surface movement and deformation caused by mining on the F5009 working face started in February 2018, and a total of 27 observations were made until August 2020. Line N, measuring the surface subsidence in the caving area, crosses the middle of the F5009 working face, and the projected positions of the selected measurement points below the working face are located $400 \mathrm{~m}$ from the open-off cut of the working face. The surface subsidence data of each measurement point online $\mathrm{N}$ are shown in Figure 9(a). The surface subsidence data of each time period of measuring point $\mathrm{n} 4$ are shown in Figure 9(b).

As shown in Figure 9(b), in comparison with solid backfill mining, the initial value of surface subsidence of the caving method was larger, reaching $60 \mathrm{~mm}$. As mining on the working face continued, the value of surface subsidence increased gradually without any sudden increase. The maximum value of subsidence of measuring point $n 4$ reached $210 \mathrm{~mm}$ by August 2020, when all of the mining operations on the working face had been completed.

The CORS monitoring system indicated a final maximum surface tilt deformation of $6.65 \mathrm{~mm} / \mathrm{m}$, a maximum curvature deformation of $0.59 \mathrm{~mm} / \mathrm{m}^{2}$, and a maximum horizontal deformation of $168.1 \mathrm{~mm}$, or $4.25 \mathrm{~mm} / \mathrm{m}$, which does not meet the surface building protection requirements.

\subsection{Comparative Analysis on Control Effect of Different} Mining Methods. A comparison of surface deformation parameters between the solid backfill mining method and the caving method is shown in Table 3.

In addition, the relationship between surface subsidence values and monitoring time was analysed for $\mathrm{T}_{3} 292$, F5001, and F5002. The monitoring data were acquired at the time points of the goaf square period, end of mining, 3 months after mining, 1 year after mining, and 2 years after mining. The analysis results showed that the surface subsidence of backfill mining was significantly affected by monitoring time. Although the surface did not show large subsidence during the mining, surface subsidence increased significantly from 3 months to 1 year after mining. The time of 2 years after backfill mining can be regarded as the time when mining was completed, and the surface subsidence above the working face did not increase further at this time.

\subsection{Determination of Surface Prediction Parameters in} Tangshan Mine. According to the surface subsidence monitoring results of the Tangshan mine of previous years, the subsidence factor of the Tangshan mine with the caving method was determined to be between 0.55 and 0.85 ; the tangent of the major effective angle was between 1.92 and 2.40; and the offset distance of the inflection point was 0 . Through parameter inversion of the surface subsidence in the $F$ zone, the subsidence factor of backfill mining was determined to be 0.028 , and the tangent of the major effective angle was 1.20, as shown in Table 4. 


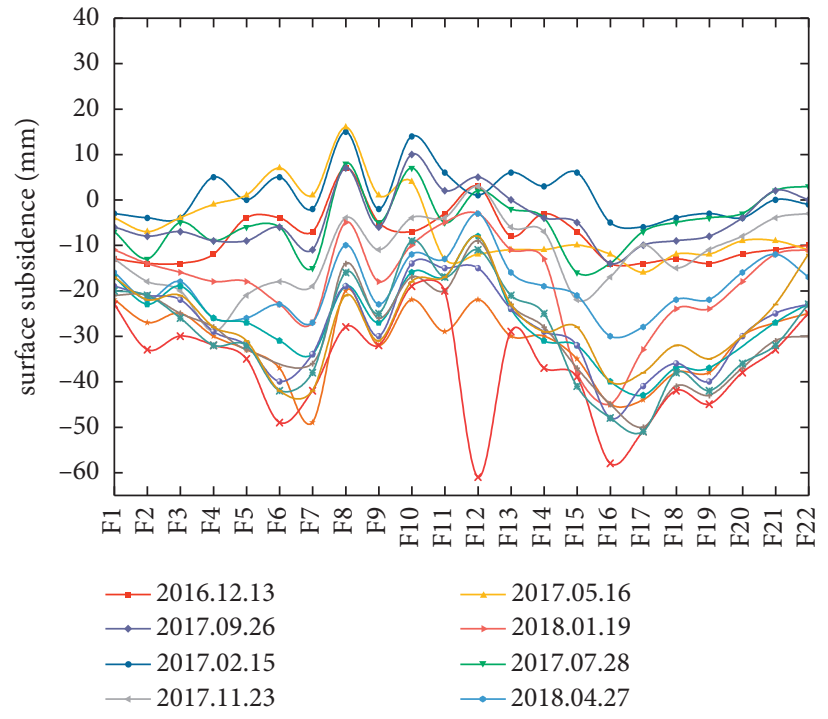

(a)

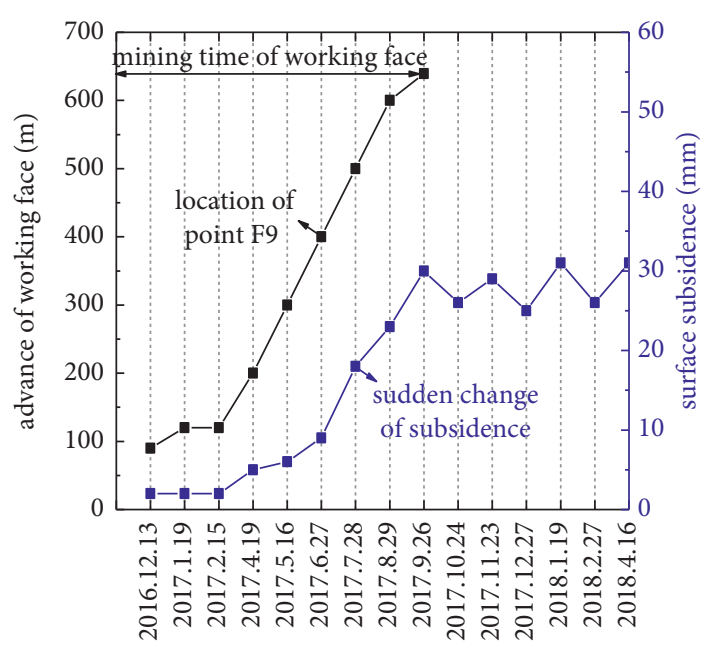

(b)

Figure 7: Surface subsidence values (a) on line F for each time period and (b) for each time period at measuring point F9.

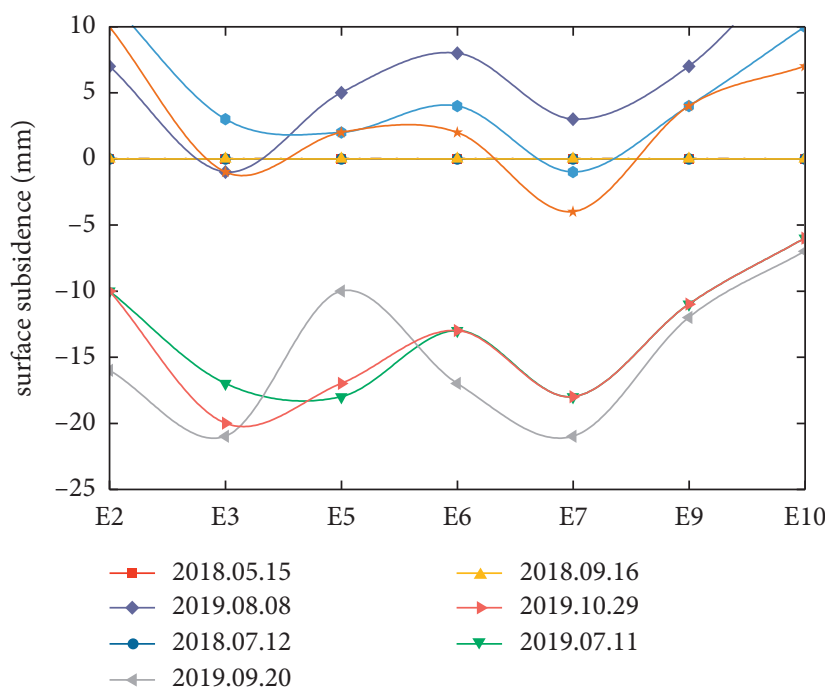

(a)

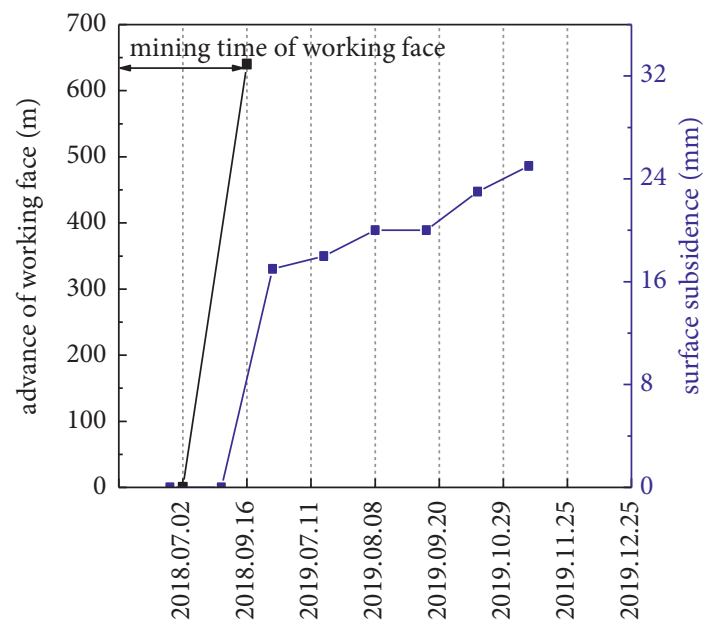

(b)

Figure 8: Surface subsidence values (a) at line E for each time period and (b) for each time period at measuring point E3.

As shown in Table 4, the surface subsidence prediction parameters currently obtained from monitoring one to two working faces are not accurate, as the subsidence factor is extremely low. The prediction with these parameters is thus not representative of the surface subsidence after mining in the area. Therefore, by comparing the predicted results of surface subsidence, considering multiple factors in the $F$ zone, the subsidence factor appropriate for the predicted subsidence with solid backfill mining of underground coal in the Tangshan mine was determined to be 0.82 , and the tangent of the major effective angle is 2.15 . At this time, the predicted result of surface subsidence is $152 \mathrm{~mm}$, which can be regarded as the final amount of surface subsidence after the end of mining in the $F$ zone.

\section{Discussion}

Surface subsidence is greatly affected by mining areas; it is necessary to analyse the influencing factors of surface subsidence. At the same time, the parameters of surface subsidence prediction will change accordingly. An analysis software was used for coal mining subsidence prediction, and the results are shown in Table 5. The surface subsidence, horizontal deformation, curvature, and tilt deformation under different influencing factors were analysed and compared. The test results obtained are shown in Figure 10.

As shown by the analysis in Figure 10, the subsidence, horizontal deformation, curvature, and tilt deformation increase gradually as the face length increases gradually. The 


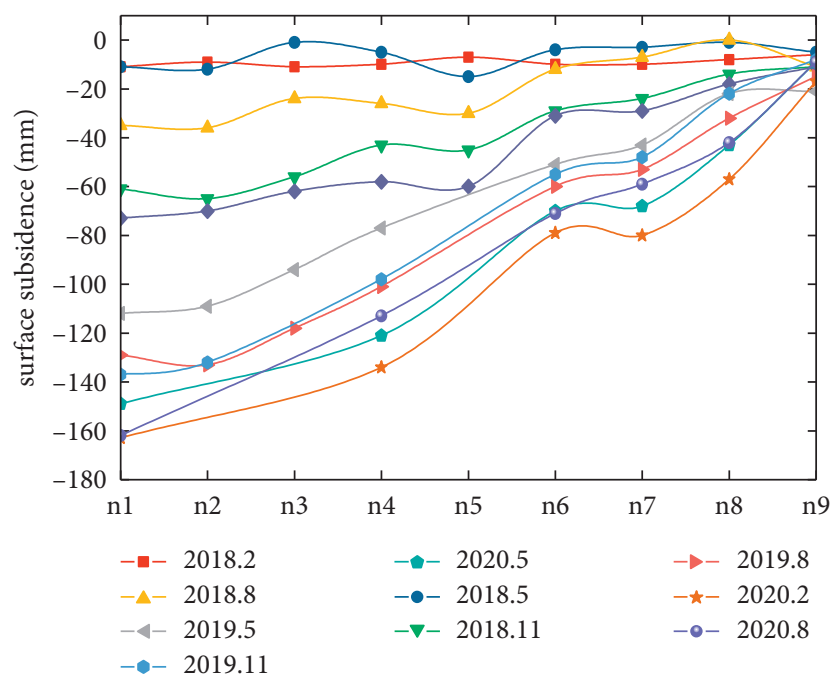

(a)

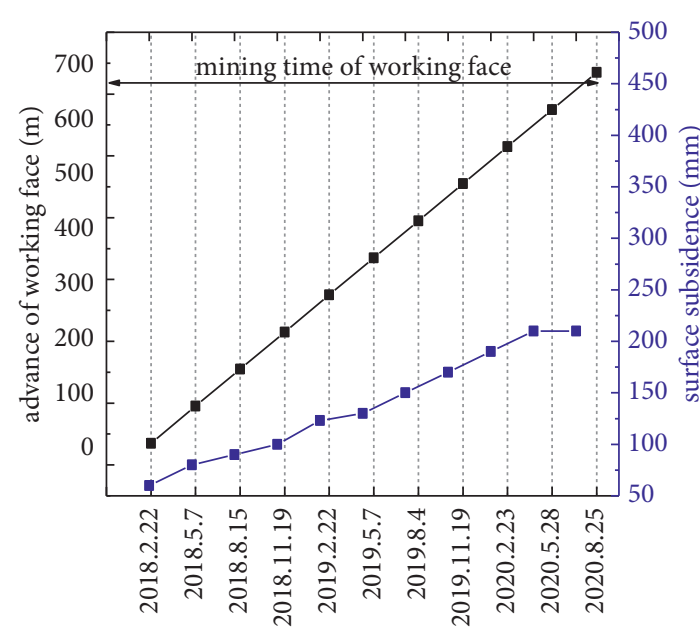

(b)

FIgURE 9: Surface subsidence values (a) on line $\mathrm{N}$ for each time period and (b) for each time period at measuring point $n 4$.

TABle 3: Comparison of surface deformation parameters between infill mining and collapse mining.

\begin{tabular}{lcccccc}
\hline $\begin{array}{l}\text { Mining } \\
\text { method }\end{array}$ & Working face & $\begin{array}{c}\text { Maximum } \\
\text { subsidence } \\
(\mathrm{mm})\end{array}$ & $\begin{array}{c}\text { Maximum tilt } \\
\text { deformation } \\
(\mathrm{mm} / \mathrm{m})\end{array}$ & $\begin{array}{c}\text { Maximum } \\
\text { curvature } \\
\text { deformation } \\
\left(\mathrm{mm} / \mathrm{m}^{2}\right)\end{array}$ & $\begin{array}{c}\text { Maximum horizontal } \\
\text { deformation value }(\mathrm{mm})\end{array}$ & $\begin{array}{c}\text { Maximum horizontal } \\
\text { deformation }(\mathrm{mm} / \mathrm{m})\end{array}$ \\
\hline Backfill & T3292 & 66 & 0.76 & 0.064 & 50.6 & 1.53 \\
method & F5001 & 31 & 1.65 & 0.094 & 7.1 & 0.84 \\
\hline $\begin{array}{l}\text { Caving } \\
\text { method }\end{array}$ & F5002 & 25 & 0.29 & 0.012 & 168.1 & 4.25 \\
\hline
\end{tabular}

TABLE 4: Calibration of projected surface parameters for the Tangshan mine.

\begin{tabular}{lccccc}
\hline Item & $\begin{array}{c}\text { Subsidence } \\
\text { factor }\end{array}$ & $\begin{array}{c}\text { Tangent of } \\
\text { major effective } \\
\text { angle }\end{array}$ & $\begin{array}{c}\text { Offset distance of } \\
\text { the inflection } \\
\text { point }\end{array}$ & $\begin{array}{c}\text { Horizontal } \\
\text { movement } \\
\text { coefficient }\end{array}$ & $\begin{array}{c}\text { Mining impact propagation } \\
\text { angle }\end{array}$ \\
\hline $\begin{array}{l}\text { Caving method } \\
\begin{array}{l}\text { Backfilling method } \\
\text { (experience) }\end{array}\end{array}$ & $0.55-0.85$ & $1.92-2.4$ & 0 & 0.33 & 82 \\
$\begin{array}{l}\text { Backfilling method } \\
\text { (measured) }\end{array}$ & $0.85-0.89$ & $1.62-2.20$ & $0.05-0.240$ & 0.33 & 82 \\
$\begin{array}{l}\text { Backfilling method } \\
\text { (simulated) }\end{array}$ & 0.028 & 1.20 & 0 & 0.33 & 82 \\
\hline
\end{tabular}

subsidence, horizontal deformation, curvature, and tilt deformation decrease gradually as the compression ratio increases gradually, and the subsidence, horizontal deformation, curvature, and tilt deformation do not change much with an increase in coal pillar width.

In particular, when the compression ratio is 0.3 , that is, the caving method is used to deal with the hollow area, the surface deformation exceeds the set damage level; thus, the compression ratio is the main influencing factor of surface deformation. From the predictive analysis of surface deformation, it is apparent that the compression ratio should be 0.6 or more to ensure the safety of surface buildings. In consideration of the influence due to early subsidence of the roof of the mining area, the compression ratio should be at least 0.8 in an actual backfilling operation.

An analysis software was used for coal mining subsidence prediction, and the results are shown in Table 6. The surface subsidence, horizontal deformation, curvature, and tilt deformation under different influencing factors were analysed and compared. The test results obtained are shown in Figure 11.

From the analysis shown in Figure 11, as the subsidence factor increases gradually, the subsidence increases gradually while the horizontal deformation, curvature, and tilt deformation tend to stabilise. As the tangent of the major effective angle increases, the subsidence, horizontal 
TABLe 5: Predicted results.

\begin{tabular}{|c|c|c|c|c|}
\hline Test & Subsidence & Horizontal deformation & Curvature & Tilt \\
\hline 1 & 108 & -0.7 & -0.01 & \pm 0.5 \\
\hline 2 & 131 & -0.9 & -0.01 & \pm 0.6 \\
\hline 3 & 152 & -1.0 & -0.01 & \pm 0.7 \\
\hline 4 & 173 & -1.1 & 0 & \pm 0.8 \\
\hline 5 & 194 & -1.2 & -0.01 & 0.9 \\
\hline 6 & 533 & -3.4 & -0.03 & 2.5 \\
\hline 7 & 304 & -2.0 & -0.02 & 1.5 \\
\hline 8 & 228 & -1.5 & \pm 0.01 & 1.1 \\
\hline 9 & 152 & -1.0 & -0.01 & \pm 0.7 \\
\hline 10 & 76 & -0.5 & 0 & 0.4 \\
\hline 11 & 153 & -1.0 & -0.01 & \pm 0.7 \\
\hline 12 & 152 & -1.0 & -0.01 & \pm 0.7 \\
\hline 13 & 152 & -1.0 & -0.01 & \pm 0.7 \\
\hline 14 & 151 & -1.0 & -0.01 & \pm 0.7 \\
\hline 15 & 150 & -0.9 & -0.01 & \pm 0.7 \\
\hline
\end{tabular}
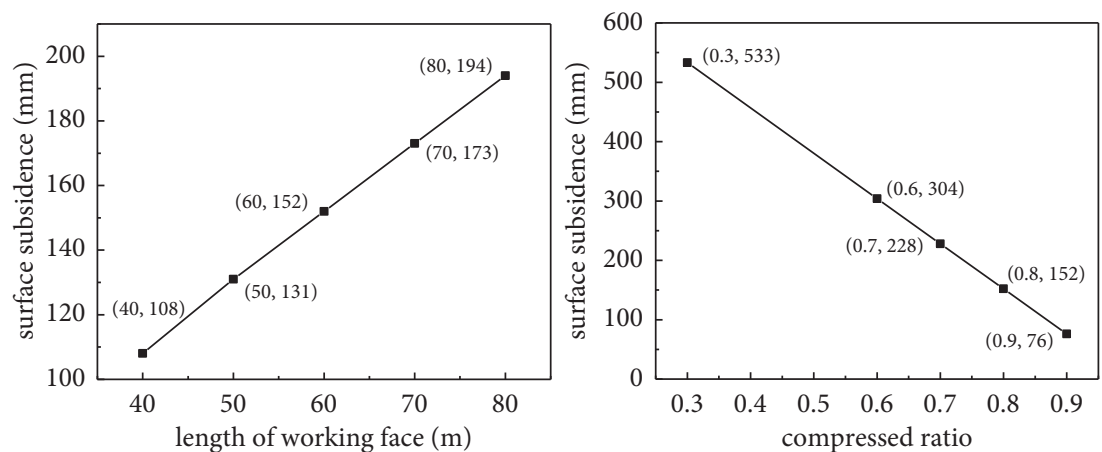

(a)
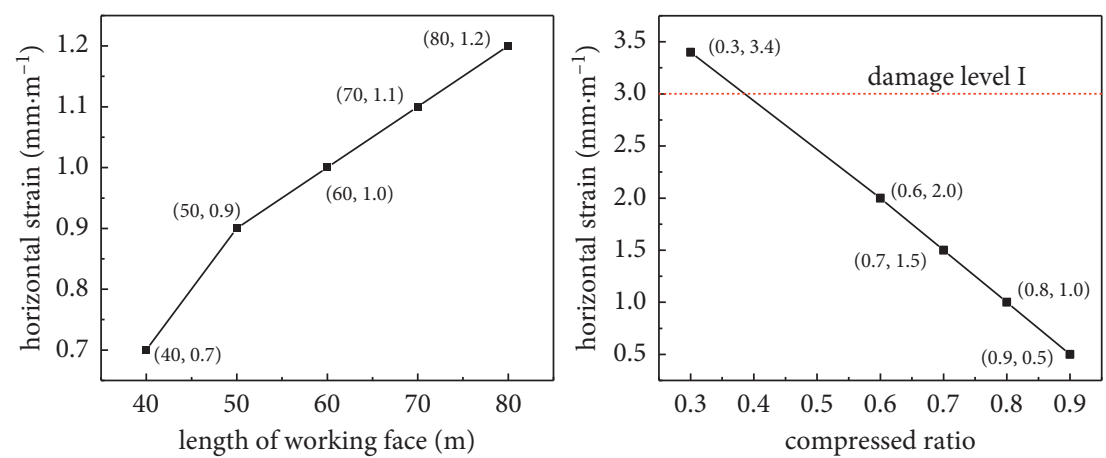

(b)
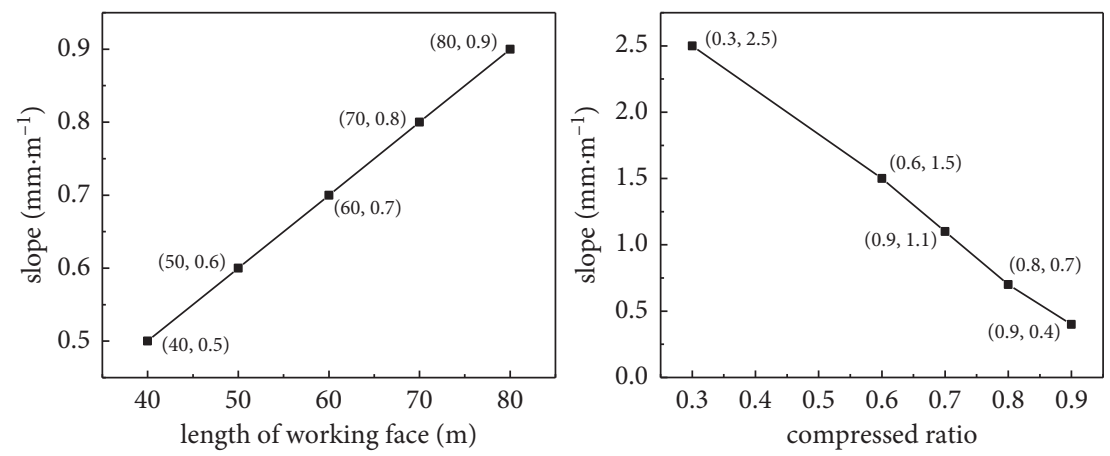
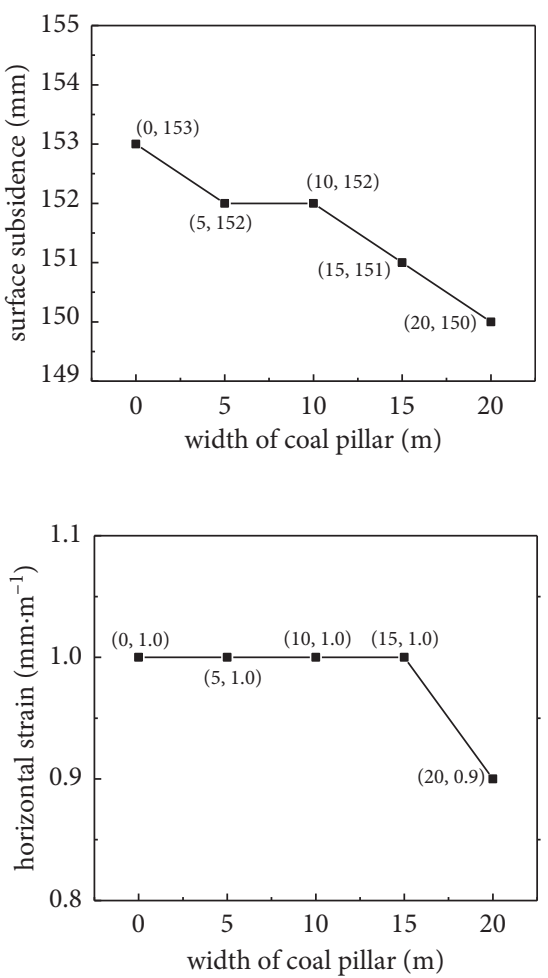

(c)

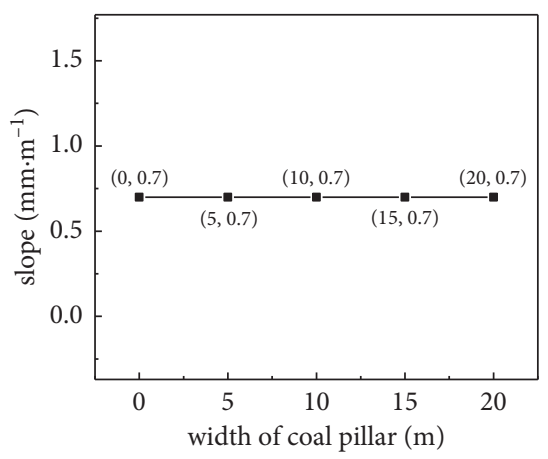

Figure 10: Experimental results: (a) surface subsidence values, (b) horizontal deformation, and (c) tilt. 
TABLe 6: Predicted results.

\begin{tabular}{lcccc}
\hline Test & Subsidence & Horizontal deformation & Curvature & Tilt \\
\hline 1 & 145 & -0.9 & -0.01 & -0.01 \\
2 & 148 & -1.0 & -0.01 & \pm 0.7 \\
3 & 152 & -1.0 & -0.01 & \pm 0.7 \\
4 & 156 & -1.0 & -0.01 & 0 \\
5 & 159 & -1.0 & -0.01 & \pm 0.7 \\
6 & 121 & -0.6 & -0.01 & -0.01 \\
7 & 137 & -0.8 & -0.5 \\
8 & 152 & -1.0 & \pm 0.01 & \pm 0.6 \\
9 & 167 & -1.2 & -0.01 & \\
10 & 181 & -1.3 & -0.01 & \pm 1.0 \\
11 & 152 & -1.0 & -0.01 & \pm 0.7 \\
12 & 152 & -1.0 & -0.01 & \pm 0.7 \\
13 & 152 & -1.0 & -0.01 & \pm 0.7 \\
14 & 152 & -1.0 & -1.0 & \pm 0.7 \\
\hline
\end{tabular}
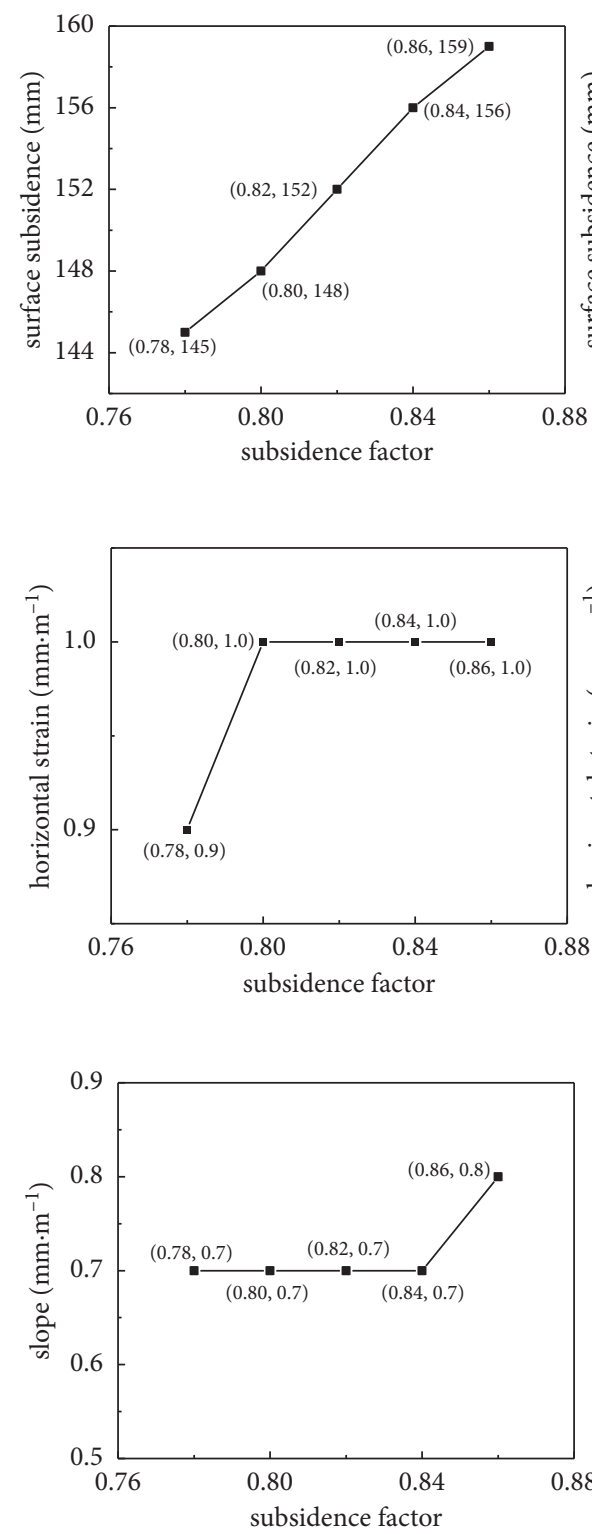
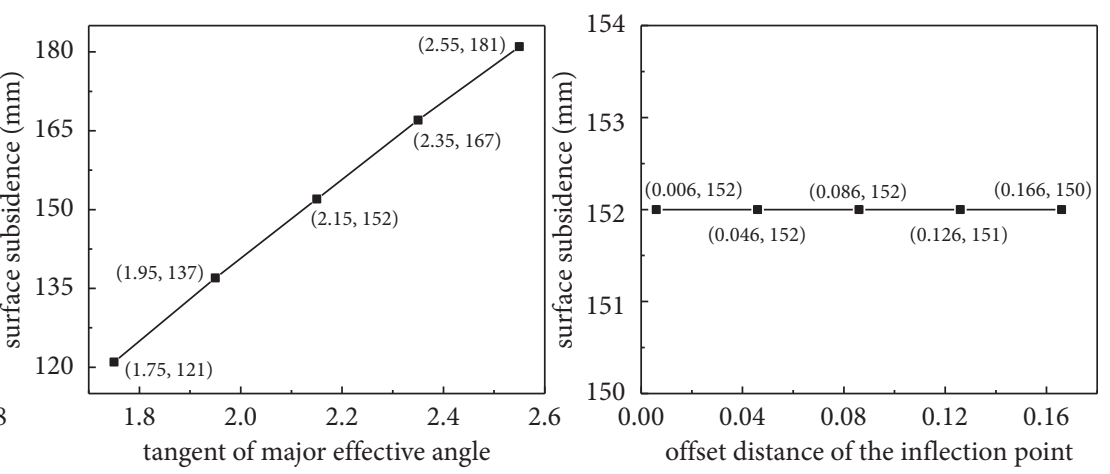

(a)
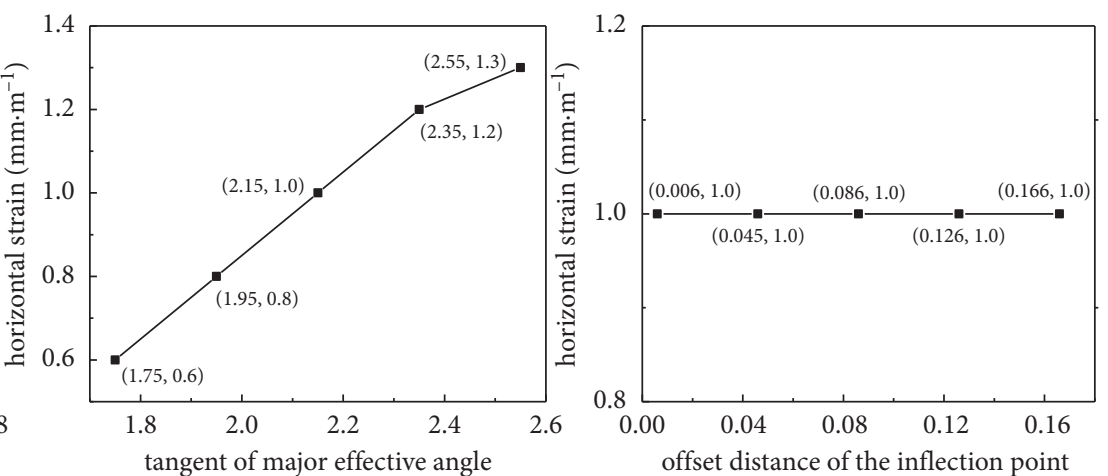

(b)

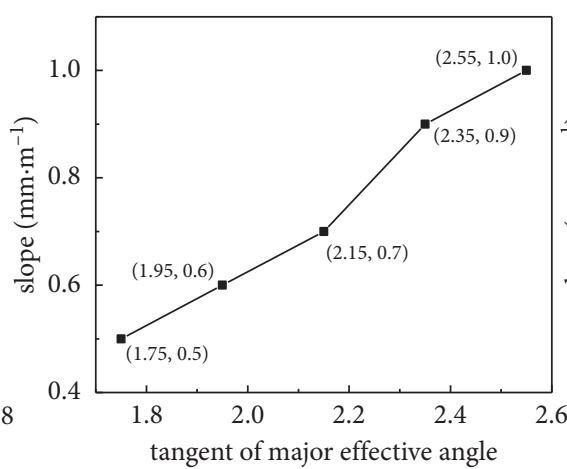

(c)

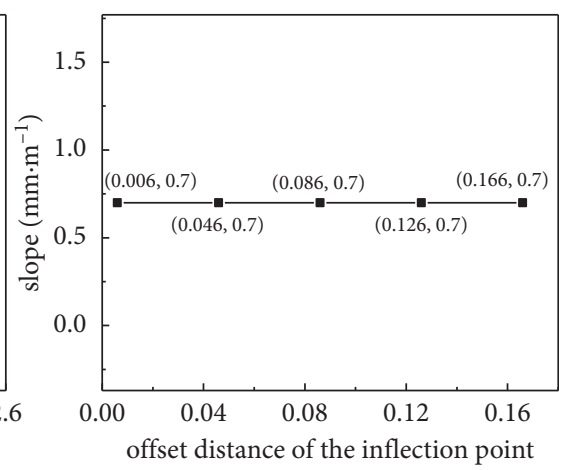

FIgURE 11: Predicted results: (a) surface subsidence values, (b) horizontal deformation, and (c) tilt. 
deformation, curvature, and tilt deformation increase gradually. As the offset distance of the inflection point increases, the subsidence, horizontal deformation, curvature, and tilt deformation do not change.

It can be seen that the subsidence factor is the main influencing factor of the surface subsidence prediction results and that the tangent of the major effective angle is the main factor affecting the prediction results of surface horizontal deformation and tilt.

\section{Conclusion}

(1) The CORS system was used to monitor the surface subsidence of coal mining under Tangshan city, which spanned more than 5 years and covered the $T$ zone and the $F$ zone, corresponding to a mining area of $150,000 \mathrm{~m}^{2}$. The monitoring results showed that the surface protection requirements of urban mining were met by solid backfill mining, which had gentler surface deformation than caving mining. The maximum subsidence in the $T$ zone after 32 months of working face mining was $66 \mathrm{~mm}$, and the maximum subsidence in the $F$ zone after 6 months of working face mining was $31 \mathrm{~mm}$.

(2) Through the multifactor surface subsidence prediction based on the probability integral method, it was concluded that surface subsidence is strongly influenced by the working face length and the compression ratio. The surface deformation increases gradually as the face length increases and the compression ratio decreases. To ensure the safety of surface buildings, the compression ratio must be at least 0.8 .

(3) By comparing the actual measurement data in the field with the quality simulation data, the subsidence factor suitable for the Tangshan mine was finally determined to be 0.82 , and the tangent of major effective angle was determined to be 2.15 , at which time the predicted results are close to the subsidence results after extensive backfill mining in the mining area.

\section{Data Availability}

The data used to support the findings of this study are included within the article.

\section{Disclosure}

This manuscript was presented as a preprint in research square (https://www.researchsquare.com/article/rs-221271/v1).

\section{Conflicts of Interest}

The authors declare that there are no conflicts of interest.

\section{Authors' Contributions}

All authors contributed equally to this research.

\section{Acknowledgments}

The authors would like to thank the staff of Tangshan mine who worked hard to monitor and got precious measured data. All authors are grateful for the financial assistance provided by the Independent Research Project of the $\mathrm{Na}$ tional Key Research and Development Program of China (2018YFC0604704).

\section{References}

[1] H. Xie, G. Feng, J. U. Yang, and S. University, "Research and development of rock mechanics in deep ground engineering," Chinese Journal of Rock Mechanics and Engineering, vol. 11, pp. 2161-2178, 2015.

[2] H. P. Xie, F. Gao, Y. Ju, M. Z. Gao, R. Zhang, and Y. N. Gao, "Quantitative definition and investigation of deep mining," Journal of China Coal Society, vol. 40, no. 1, pp. 1-10, 2015.

[3] H. P. Xie, H. W. Zhou, D. J. Xue, H. W. Wang, R. Zhang, and F. Gao, "Research and consideration on deep coal mining and critical mining depth," Journal of China Coal Society, vol. 37, no. 37, pp. 535-542, 2012.

[4] L. Yuan, "Thoughts and suggestions on cracking major scientific and technological problems in deep coal mining," Science and Technology Review, vol. 34, no. 2, p. 1, 2016.

[5] J. Zhang, N. Zhou, Y. Huang, and Q. Zhang, "Impact law of the bulk ratio of backfilling body to overlying strata movement in fully mechanized backfilling mining," Journal of Mining Science, vol. 47, no. 1, pp. 73-84, 2011.

[6] Z. Qiang, Z. Jixiong, H. Yanli, and J. Feng, "Backfilling technology and strata behaviors in fully mechanized coal mining working face," International Journal of Mining Science and Technology, vol. 22, no. 2, pp. 151-157, 2012.

[7] D. Zhou, K. Wu, X. Miao, and L. Li, "Combined prediction model for mining subsidence in coal mining areas covered with thick alluvial soil layer," Bulletin of Engineering Geology and the Environment, vol. 77, no. 1, pp. 283-304, 2018.

[8] J. Zhang, Q. Zhang, A. J. S. Spearing, X. Miao, S. Guo, and Q. Sun, "Green coal mining technique integrating miningdressing-gas draining-backfilling-mining," International Journal of Mining Science and Technology, vol. 27, no. 1, pp. 17-27, 2017.

[9] W. Yin, X. Miao, J. Zhang, and S. Zhong, "Mechanical analysis of effective pressure relief protection range of upper protective seam mining," International Journal of Mining Science and Technology, vol. 27, no. 3, 2017.

[10] H. Yan, J. Zhang, N. Zhou, S. Zhang, and X. Dong, "Shaft failure characteristics and the control effects of backfill body compression ratio at ultra-contiguous coal seams mining," Environmental Earth Sciences, vol. 77, no. 12, p. 458, 2018.

[11] J. Zhang, Q. Sun, A. Fourie, F. Ju, and X. Dong, "Risk assessment and prevention of surface subsidence in deep multiple coal seam mining under dense above-ground buildings: case study," Human and Ecological Risk Assessment, vol. 25, no. 4, pp. 1-15, 2018.

[12] Y. Hao, Z. Jixiong, Z. Sheng, and Z. Nan, "Physical modeling of the controlled shaft deformation law during the solid backfill mining of ultra-close coal seams," Bulletin of Engineering Geology and the Environment, vol. 78, no. 5, pp. 3741-3754, 2019.

[13] S. Qiang, Z. Jixiong, Z. Qiang, and Y. Hao, “A case study of mining induced impacts on the stability of multi-tunnels with the backfill mining method and controlling strategies," Environmental Earth Sciences, vol. 77, no. 6, pp. 1-13, 2018. 
[14] Z. Qiang, Z. Ji-Xiong, Q. I. Wen-Yue, Z. Nan, and T. Yang, "Structure optimal design research on backfill hydraulic support," Journal of Central South University, vol. 24, no. 7, pp. 1637-1646, 2017.

[15] H. Li, J. Zha, G. Guo, N. Zheng, and Y. Gong, "Improvement of resource recovery rate for underground coal gasification through the gasifier size management," Journal of Cleaner Production, vol. 259, Article ID 120911, 2020.

[16] X. Liu, G. Guo, and H. Li, "Thermo-mechanical coupling numerical simulation method under high temperature heterogeneous rock and application in underground coal gasification," Energy Exploration and Exploitation, vol. 4, Article ID 014459871988898, 2020.

[17] G. Zhang, Y. Lv, G. Guo, and C. Yu, "Monitoring deep mining similarity material model of super-thick and weak cementation overburden by digital photography," IOP Conference Series: Materials Science and Engineering, vol. 782, Article ID 022028, 2020.

[18] W. Qi-Chun, G. Guang-Li, Z. Jian-Feng, and X. Yong, "Study on surface ground movement law of coal rejects backfill mining under thick and loose overburden strata," Coal Science and Technology, vol. 41, 2013.

[19] H. Li, G. Guo, and N. Zheng, "Influence of coal types on overlying strata movement and deformation in underground coal gasification without shaft and prediction method of surface subsidence," Process Safety and Environmental Protection, vol. 120, pp. 302-312, 2018.

[20] Q.-1. Yao, Z. Xia, C.-j. Tang et al., "Characteristics of heavy metal ion adsorption by silty mudstones in coal mine goafs," Geofluids, vol. 2020, no. 4, 17 pages, Article ID 8560151, 2020.

[21] Z. Chong, Q. Yao, X. Li, and K. Shivakumar, "Acoustic emission investigation on scale effect and anisotropy of jointed rock mass by the discrete element method," Arabian Journal of Geosciences, vol. 13, no. 9, pp. 1-14, 2020.

[22] J. Fei, L. I. Xiangdong, W. Bing, and L. I. Qiang, "Influence analysis of strata movement in subsequent cemented filling of panel second-step stopes," Mining Research and Development, vol. 36, no. 10, pp. 94-98, 2016.

[23] D. X. Niu, P. Wang, Q. Wang, F. Y. Hua, F. Wang, and Z. H. Cai, "Analysis of the power plant security management capability based on the ISM and AHP," Advanced Materials Research, vol. 960-961, pp. 1477-1482, 2014. 